\title{
Bases moleculares de la enfermedad de Alzheimer. Perspectivas de nuevos enfoques terapéuticos. ${ }^{1}$
}

Jorge A. Huete-Pérez ${ }^{1}$ y Elisa Sentis ${ }^{1}$

Centro de Biología Molecular (CBM), Facultad de Ciencia, Tecnología y Ambiente, Universidad Centroamericana, UCA. Rotonda Rubén Darío, 500mts al oeste, Apto. Postal 69. Managua, Nicaragua. Tel: 278-3923 Ext. 1189. E-mail: huete@ns.uca.edu.ni

EL ESTUDIO DE LA ENFERMEDAD DE ALZHEIMER HA AVANZADO mucho en los últimos años gracias al descubrimiento de los genes implicados, sus mutaciones y variantes. Este cúmulo de conocimientos se ha ido organizando en diferentes hipótesis que dan mayor importancia a uno u otro factor genético. Con el progreso acelerado de la fármaco-genómica, se han identificado nuevos factores genéticos de los procesos patogénicos, lo cual debería conllevar a nuevas formas de tratamiento. En este artículo de revisión abordamos las bases moleculares y genéticas del mal de Alzheimer y discutimos las posibles nuevas terapias.

The study of Alzheimer's Disease (AD) has advanced much in the last few years, thanks to the discovery of associated genes and their variants and mutations. This accumulation of knowledge has led to the creation of various hypotheses concerning $\mathrm{AD}$ which give greater relevance to one or other genetic factor. With the accelerated pace of development in the area of pharmaceutical genomics, new genetic factors involved in the pathogenic process have been identified, which should lead to new avenues for treatment. In this review article we discuss the molecular and genetic bases for $\mathrm{AD}$ as well as potential new therapies.

\section{Introducción}

La enfermedad de Alzheimer (en adelante, EA) es la causa más común de demencia progresiva, afectando a más del 5\% de los mayores de 65 años. Dado que después de esa edad la prevalencia se duplica cada 5 años, se estima que el porcentaje alcanza el 50\% en personas de 85 años de edad (Forsyth y Ritzline, 1998; Cummings, 2004). En los Estados Unidos y algunos países europeos, el problema se viene considerando cada vez más como una problemática prioritaria de salud pública debido a que en estos países industrializados -en donde la población de adultos mayores representa un porcentaje alto- la prevalencia va en aumento. También causan preocupación las consecuencias familiares, sociales y económicas (gastos en salud) de la enfermedad. Según datos publicados (Plasman et al., 
2007) en noviembre pasado, en Estados Unidos el 10\% de las personas de 70 años padecen de Alzheimer. Por otra parte, según un informe de la Asociación de Alzheimer de EEUU², la cifra de hispanos en Estados Unidos que sufrían de Alzheimer en el 2004 se estimó en 200 mil y se calcula que la cifra aumentará hasta millón y medio en el 2050. En España se calculan unos 800 mil casos con un costo individual de atención médica de entre 9 mil y 35 mil euros anuales. Según estimados de la Fundación Alzheimer de Nicaragua, en este país de apenas 5 millones de habitantes predominantemente jóvenes, hay entre 15 y 20 mil personas afectadas por esta enfermedad. ${ }^{3}$

A pesar de que la primera descripción del problema se publicó hace cien años (Alzheimer, 1907), las medicinas con las que hoy en día se trata a los pacientes apenas logran algún beneficio sintomático y no curan la enfermedad.

Desde los primeros reportes sobre la EA, se ha reconocido la muerte neuronal en las áreas límbicas del cerebro y dos tipos de lesiones que caracterizan a este mal: las placas amiloides y los ovillos neurofibrilares. Las primeras contienen depósitos extracelulares del polipéptido Beta-amiloide (AB), mientras que los segundos consisten principalmente de proteína Tau.

Con el progreso acelerado de la investigación biomédica reciente, en particular de la fármaco-genómica, se han identificado nuevos factores genéticos y sus contribuciones en los procesos patogénicos son objeto de estudio de muchos grupos de investigación. Por lo tanto se avizoran también mejores perspectivas de tratamiento. En esta revisión abordamos las bases moleculares y genéticas del mal de Alzheimer a la luz de los hallazgos recientes y discutimos las posibles nuevas terapias.

\section{Bases moleculares de la EA}

La identificación de factores genéticos relacionados al mal de alzheimer es un requerimiento fundamental para el diseño de nuevas terapias, una vez comprendidos los procesos patogénicos. Aquí es importante enfatizar la clasificación de la EA en dos grandes grupos: de inicio precoz y de inicio tardío, según la manifestación de los síntomas, entre los 35 y 65 años o después de los 65. Mientras en la EA de inicio precoz la enfermedad sigue un patrón de herencia autosómica dominante, la EA de tipo tardío suele presentar poca agregación familiar o no seguir patrones de herencia monogénica, sino que obedece a la interacción de herencia más bien poligénica con factores ambientales aún desconocidos.

El estudio genético de la EA de inicio precoz se facilitó por la investigación de familias afectadas, conllevando al descubrimiento de mutaciones de genes determinados, como el que codifica la proteína precursora amiloidea (Van Broeckhoven, 1995), APP y Presenilina 1 y 2 (Schellenberg et $a l$., 1992), que se presentan como causas de la enfermedad. No obstante, en el caso de la EA de tipo tardío, el gen más relevante, Apolipoproteína E (ApoE), tiene implicaciones apenas como factor de riesgo porque la presencia de ciertas variaciones como la ApoE-e4 (Saunders et al., 1996) no garantiza inequívocamente el desarrollo de la enfermedad. 


\section{Proteina precursora amiloidea (APP)}

Aun se desconoce la función celular específica de la APP y tampoco está clara su relación con la enfermedad. Sin embargo, es significativo que en circunstancias de estrés celular la expresión de APP se vea aumentada. Estructuralmente es un tipo de proteína de membrana que se expresa en diversos tejidos, concentrándose en las sinapsis.

El gen APP se localiza en el cromosoma 21 (Tanzi et al., 1987), consiste de 19 exones y codifica una proteína precursora de aproximadamente entre 695 y 770 aminoácidos. La composición de péptidos $\mathrm{AB}$ proviene de partes de los exones 16 y 17. El desbalance de digestión que produce los fragmentos $\mathrm{AB}$ conlleva al exceso de los fragmentos más largos que son más neurotóxicos y tienden a formar agregados.

Entre las variantes mutantes más comunes de APP se destacan la sustitución de isoleucina por valina en el aminoácido 717 (Goate $e t$ al., 1991), fenilalanina por glicina en la misma posición 717 y la doble mutación de los aminoácidos 670 y 671 (mutación Suiza, Bogdanovic et al., 1994).

Diferentes mutaciones en el gen que codifica la proteína PPA se consideran causantes de entre 5 y $20 \%$ de los casos de EA de inicio precoz. Los individuos que presentan mutaciones en este gen generalmente desarrollan la enfermedad alrededor de los 50 años de edad. Se conocen al menos 6 mutaciones diferentes en este gen y aunque varían en la posición del gen, todas las variantes están muy próximas, de manera que se ha ubicado una región de importancia dentro del gen.

El tamaño del péptido $\mathrm{AB}$ producto de la hidrólisis de la APP, oscila entre 39 y 43 aminoácidos, significando variaciones en el procesamiento de la proteína precursora de amiloide. Dicho procesamiento ocurre por la acción de diversas proteínas proteasas. En particular, la digestión por la acción combinada de $\beta$ y $\Upsilon$ secretasas, puede producir diversos tipos de $\mathrm{AB}$, siendo la forma $\mathrm{AB} 40$ (de 40 aminoácidos) la predominante y aparentemente menos tóxica dada su mejor solubilidad, en comparación con las formas AB42 ó AB43 más tóxicas y menos solubles.

\section{Presenilinas 1 y 2 (PSEN 1, PSEN 2)}

Los genes PSEN 1 y 2 son homólogos en gran proporción. Mientras el gen de PSEN 1 se encuentra ubicado en el cromosoma 14, el de la PSEN 2 se ubica en el cromosoma 1. Las mutaciones en el gen de PSEN 1 representan cerca de la mitad de todos los casos de EA de inicio precoz. En cambio, la ocurrencia de PSEN 2 es poca. Se ha descubierto que las proteínas presenilinas se localizan en la región postsináptica y que son indispensables en la embriogénesis normal del sistema nervioso central.

Se han encontrado más de 75 mutaciones diferentes en el gen PSEN 1 de familias de diversos orígenes étnicos (Hardy, 1997). Estas personas pueden presentar la enfermedad entre los 30 y 60 años de edad. Los familiares generalmente presentan el mismo tipo de mutación y la edad de presentación también suele ser la misma. Dado que hay casos de personas 
que presentan mutaciones tipo PSEN 2 pero que no presentan la enfermedad, algunos investigadores las consideran menos agresivas.

La región codificadora está compuesta por 10 exones enumerados del 3 al 12 . Pueden ocurrir isoformas de la proteína mediante "splicing” alternativos del exon 3 ó del 8, además, también por splicing se pude incorporar un nuevo exon entre el 10 y el 11.

\section{Tau}

Los ovillos neurofibrilares característicos de la EA consisten principalmente de filamentos precipitados de la proteína Tau. En condiciones normales, la proteína Tau facilita la polimerización de la tubulina en la célula conduciendo a la formación de microtúbulos, estabilizándolos y facilitando el transporte intracelular a nivel de vesículas. Además, se supone que facilita el crecimiento axonal.

El gen que codifica para la proteína Tau se localiza en el cromosoma 17 y hasta ahora se han encontrado más de 20 mutaciones. Estas mutaciones favorecen la formación de los ovillos característicos de Taupatías. En condiciones patológicas, Tau se encuentra hiperfosforilada y los filamentos se agrupan en nódulos altamente hidrofóbicos que se precipitan al interior de la célula causando la muerte celular.

También en casos patológicos la proteína Tau suele ligarse con actina. Se han observado depósitos similares en otros trastornos degenerativos del sistema nervioso como la degeneración frontotemporal lobar (FTLD).

\section{Apolipoproteína E (ApoE)}

La asociación de una o dos copias de la ApoE alelo e4 del cromosoma 19 (genotipos posibles e2/e4; e3/e4; e4/e4) con la EA tipo tardío ya está muy bien documentada (Khachaturian, 2004; Martins et $a l ., 2005)$, siendo el genotipo homocigoto e4/e4 el que tiene mejor asociación.

En individuos que presentan síntomas de EA, en presencia del genotipo e4/e4 la probabilidad de que el diagnóstico sea certero aumenta a 97\%. Estas observaciones también se han validado en poblaciones afro-americanas (Green, 2002) y en hispanos caribeños (Romas $e t$ $a l ., 2002$ ). Por otra parte, hay evidencias indicando que (a diferencia de e4) el alelo e2 podría presentar un efecto protector en cuanto al riesgo de EA.

\section{Otros genes}

La esperanza de los científicos con cada nuevo gen identificado es poder desarrollar nuevos medicamentos y métodos de diagnósticos. Recientemente se han señalado otros genes que aparentan jugar roles importantes en la patología de Alzheimer (Cuadro 1). 
Cuadro 1. Resumen de los factores genéticos en la enfermedad de Alzheimer.

\begin{tabular}{|l|l|}
\hline Tipo de asociación con la EA & Factor genético \\
\hline $\begin{array}{l}\text { Genes con mutaciones implicados en } \\
\text { la enfermedad de Alzheimer de inicio } \\
\text { precoz (genes determinísticos). }\end{array}$ & $\begin{array}{l}\text { APP, gen de la Proteína Precursora Amiloidea } \\
\text { (cromosoma 21) }\end{array}$ \\
\hline $\begin{array}{l}\text { PSEN 1 y 2, genes de la Presenilina 1 y } 2 \\
\text { (cromosomas 14 y 1, respectivamente) }\end{array}$ \\
$\begin{array}{l}\text { Genes de susceptibilidad, de los cuales } \\
\text { predisten algunas variantes que pueden } \\
\text { de Alzheimer de tipo tardío. }\end{array}$ & $\begin{array}{l}\text { ApoE, Apolipoproteína E (ApoE-e4), este } \\
\text { representa el primer factor de riesgo genético } \\
\text { descubierto para esta forma de la enfermedad } \\
\text { SORL-1, ciertas variantes del gen son más } \\
\text { comunes en personas enfermas que en las }\end{array}$ \\
\hline & saludables \\
\hline $\begin{array}{l}\text { Otros genes cuyo rol parece importante } \\
\text { pero que se desconoce su relación } \\
\text { genética o cuya implicación directa } \\
\text { está aún por confirmarse. }\end{array}$ & $\begin{array}{l}\text { Gen de la proteína Tau } \\
\text { Gen de la alfa-2-macroglobulina } \\
\text { Gen de la alfa-antiquimiotripsina } \\
\text { VLDL gen del receptor de lipoproteínas de } \\
\text { muy baja densidad } \\
\text { Gen de la butiril colinesterasa K } \\
\text { Gen de ubiquitina } \\
\text { Gen de la Catepsina D } \\
\text { Gen de la Enzima convertidora de la angioten- } \\
\text { sina } \\
\text { CoxI y CoxII, genes mitocondriales }\end{array}$ \\
\hline
\end{tabular}

Cada nuevo gen encontrado con implicaciones en la EA tiene que someterse al análisis de relación genotipo-fenotipo, como se ha hecho anteriormente con APP, PSEN 1, PSEN 2 y APOEE-e4. El problema con todos los genes que van apareciendo como implicados en la EA es que no muestran una correlación consistente a través de los diferentes sets de resultados ni una relación congruente con los conocimientos hasta ahora aceptados sobre la enfermedad. Muchos estudios de tipo caso-control y asociaciones de genes con la enfermedad demuestran serias contradicciones (Liang et al., 2007; Rodríguez-Manotas, et $a l ., 2007)$. Esta debilidad hace que en la comunidad científica cada nuevo gen se reciba con escepticismo.

Un estudio reciente que abarcó más de 6 mil participantes de diferentes grupos étnicos encontró que las personas portadoras de variaciones del gen SORL-1 tendrían un mayor riesgo de desarrollar la EA de inicio tardío (Rogaeva et al., 2007; Lee et al., 2007). Los autores del estudio aducen que algunas variantes de SORL-1 reducen la expresión del gen y modifican el tráfico celular de APP, conduciendo a la formación de AB tóxica. Se conoce que la proteína SORL-1 está involucrada en el procesamiento y tráfico de la proteína APP, está última implicada en la formación de depósitos amiloides. Se piensa que la SORL-1 protege del Alzheimer dirigiendo la APP hacia los endosomas en donde ésta es fragmentada. 
Estos hallazgos son especialmente significativos no sólo por el gran número de participantes, sino también porque el rango racial y étnico de los participantes fue bastante amplio, incluyendo europeos blancos, negros, así como poblaciones de hispano-caribeños y de origen israelí-árabe, estos dos últimos con gran incidencia de EA. En estudios subsiguientes se deberá confirmar si realmente estas variantes se asocian o no y valorar el riesgo real que significan las variantes del SORL-1.

\section{Hipótesis sobre el mecanismo causal}

La identificación de los genes implicados en la EA ha impulsado el establecimiento de diferentes corrientes de opinión científica formalizadas como hipótesis que tratan de explicar las causas y el mecanismo patológico (Cuadro 2).

\section{Hipótesis de la cascada amiloidea}

Hasta hace poco la explicación más aceptada sobre la causa de la enfermedad ha sido la "hipótesis amiloidea (HA) o cascada amiloidea", radicada fundamentalmente en que la producción amplificada del péptido $\mathrm{AB}$, en particular $\mathrm{AB} 42$ y $\mathrm{AB} 43$, conduce a la formación de placas seniles consistentes de depósitos o agregados AB (Hardy y Selkoe, 2002). La toxicidad de estos depósitos conduciría a su vez a la formación de los ovillos neurofibrilares con la posterior muerte celular. La principal debilidad de esta hipótesis es que no señala el mecanismo por el cual se crea el desequilibrio de producción de las placas amiloides. La excepción son las mutaciones del gen APP que conllevan inevitablemente a variaciones en la producción de fragmentos $\mathrm{AB}$ insolubles.

Algunos hallazgos recientes han venido a dar mayor validez a la hipótesis amiloidea. El rol patogénico de $\mathrm{AB}$ implica que las formas solubles de $\mathrm{AB}$ causan pérdida de la memoria (Lesné $e t$ al., 2006) y su adhesión a las dendritas. Con el clonaje de PSEN 1 y PSEN 2 se ha comprendido que sus proteínas afectan el metabolismo de APP, actuando directamente sobre la $\Upsilon$ - secretasa. En la cascada patogénica de EA las alteraciones del procesamiento de APP son anteriores a las alteraciones de Tau (Rapoport, 2002). Los experimentos de cruces entre ratones transgénicos que expresan APP con otros deficientes de ApoE demuestran una reducción significativa de depósitos $\mathrm{AB}$ en las crías, lo que conduce a pensar que el rol de la APOEE en la patogénesis muy probablemente involucre el metabolismo de AB (Bales et al., 2002).

\section{Hipótesis de la Presenilina}

El punto de partida de la hipótesis que explica la patología a partir de la pérdida de función de la presenilina lo constituyen los recientes experimentos con ratones transgénicos, en los cuales se ha inactivado selectivamente la acción de las presenilinas (Saura, 2005). En particular hay dos argumentos de peso en los que se apoya esta nueva hipótesis. Por un lado, mientras los modelos de ratones en que se sobre-expresa la producción del amiloide $\mathrm{AB}$ no necesariamente conllevan a neurodegeneración, la inactivación condicional de PSEN 1 sí conlleva a la pérdida progresiva de la memoria y neurodegeneración. 
Además, los inhibidores de $\gamma$ secretasa inducen el incremento de depósitos de AB y causan los mismos efectos observados en los casos de mutaciones de PSEN 1, que es ella misma una $\gamma$ secretasa. En otras palabras, las mutaciones de los genes PSEN 1 y 2 conllevan a la neurodegeneración, incrementando la producción de placas amiloides y acaso facilitando los procesos de apoptosis neuronal. Estas investigaciones indican que la disminución parcial de la actividad de PSEN 1 explica la pérdida de la memoria y la neurodegeneración de la patogénesis de la enfermedad (Shen y Kelleher, 2007).

Si bien con esta hipótesis no se desprecia la importancia de la acumulación del péptido $\mathrm{AB}$ en la patogénesis de la enfermedad, se sugiere que la importancia se debe más bien a que los altos niveles de $\mathrm{AB}$ interfieren con el funcionamiento normal de la Presenilina, conllevando a la pérdida de la función de estas proteínas.

\section{Hipótesis de Tau}

A partir de estudios de 2007 con ratones transgénicos se ha sugerido que la patología de la EA, incluyendo el comportamiento del oligopéptido $\mathrm{AB}$, depende de la molécula Tau (Roberson, 2007). Los investigadores lograron reducir a un mínimo la actividad de la proteína Tau endógena en ratones creados con una característica de superproducción de AB. Mientras los ratones con niveles normales de Tau manifestaron pérdida de memoria asociada a la edad, comportamiento anormal y depósitos de placas amiloideas, los ratones que expresaban niveles disminuidos de Tau, si bien manifestaron el patrón ordinario de acumulación de placas, en cambio no presentaron pérdida de memoria ni anormalidades de comportamiento.

La implicación derivada de estos estudios es que los efectos patológicos provenientes de las placas amiloides, podrían involucrar la disrupción de la función sináptica. Sin embargo, el papel preciso que juega Tau en dicha disrupción aun queda por determinarse. En resumen, según la hipótesis de Tau, toda patología presentada en la EA proviene del evento primario en que Tau ha perdido su función.

\section{Hipótesis colinérgica}

El razonamiento de fondo utilizado por la hipótesis colinérgica atribuye a la falta de acetil colina y destrucción de las neuronas colinérgicas, así como el consecuente déficit de la neuro-transmisión colinérgica central como causas importantes que explican los síntomas cognitivos y no-cognitivos observados en los pacientes (Cummings y Back, 1998). Bajo este principio se promovió la utilización de inhibidores de la enzima Acetil Colina Esterasa, ACE, y de la Butiril-colina Esterasa (BCE), las cuales degradan por hidrólisis el neurotransmisor acetil colina. La inhibición de estas enzimas conllevaría al aumento de la concentración del neurotrasmisor y a la mejoría del déficit colinérgico.

\section{Otras hipótesis}

Algunos investigadores le dan mayor importancia a otros factores como el desbalance de las concentraciones de calcio. La destrucción de las células nerviosas podría deberse a las 
altas concentraciones de calcio observadas en pacientes con EA.

Otros científicos piensan que la enfermedad se desencadena a partir de la infección con patógenos virales que causarían daños cerebrales. En particular, uno de los virus sospechosos es el del herpes labial. La evidencia fundamental es que se ha encontrado una importante acumulación del virus en los cerebros de pacientes que padecen de Alzheimer (Burgos $e t$ al., 2003; Bullido et al., 2007). Se ha comprobado una asociación genética de alto riesgo para EA, demostrándose que las personas que poseen la variante de la proteína ApoE-e4 y que presentan a la vez una forma determinada del gen TAP2 tienen mayores riesgos de padecer la enfermedad. El virus utiliza el gen TAP2 para evadir la respuesta inmune. Otra asociación encontrada es que en cerebros de pacientes con Alzheimer la proteína Kinasa $R$ (PKR), importante para la inhibición de la síntesis de proteínas, se encuentra activada por el virus del herpes.

Otra hipótesis que ha venido adquiriendo mayor solidez argumenta que la enfermedad aparece como resultado de la inflamación, con lo que se forman metabolitos anormales. Estos metabolitos serían responsables de modificar el empaquetamiento normal del $\mathrm{AB}$ (Zhang et al., 2004).

Cuadro 2. Resumen de hipótesis que tratan de explicar la patogénesis de la EA

\begin{tabular}{|l|l|}
\hline Hipótesis y principales postulados & Bibliografía básica \\
\hline $\begin{array}{l}\text { Hipótesis de la cascada amiloidea. La acumulación de } \\
\text { placas AB en el cerebro es la causa principal de la patogéne- } \\
\text { sis en EA. Todos los demás procesos patogénicos, incluyen- } \\
\text { do la formación de ovillos neurofibrilares (Tau), resultan del } \\
\text { desequilibrio entre la producción de AB y su eliminación. }\end{array}$ & $\begin{array}{l}\text { Selkoe, } 1991 \\
\text { Hardy y Helkoe, } 2002\end{array}$ \\
\hline $\begin{array}{l}\text { Hipótesis de la Presenilina. La pérdida de la memoria y } \\
\text { la neurodegeneración observadas en la EA se deben a la } \\
\text { pérdida parcial de la función de las Presenilinas. La acu- } \\
\text { mulación de AB no es una característica obligatoria en las } \\
\text { demencias. Los inhibidores de } \gamma \text {-secretasas usados como } \\
\text { recursos terapéuticos más bien empeorarían la neurodegen- } \\
\text { eración y la demencia. }\end{array}$ & $\begin{array}{l}\text { Saura, 2005 } \\
\text { Shen y Kelleher, } 2007\end{array}$ \\
\hline $\begin{array}{l}\text { Hipótesis de Tau. La reducción de la actividad de Tau, } \\
\text { principal componente de los ovillos neurofibrilares, previene } \\
\text { las perturbaciones de comportamiento, pérdida de memoria } \\
\text { y muerte súbita. En condiciones patológicas Tau interactúa } \\
\text { con actina en la deformación de dendritas y la plasticidad } \\
\text { sináptica. La Tau potencia los efectos de AB. Los oligopép- } \\
\text { tidos AB prefibrilares en conjunto con Tau destruyen los } \\
\text { microtúbulos conllevando a daños en las sinapsis. }\end{array}$ & $\begin{array}{l}\text { Koberson } \text { et al., } 2007 \\
\text { Fulga } \text { et al., 2007 }\end{array}$ \\
\hline
\end{tabular}


Hipótesis colinérgica. La falta de acetil colina, la destrucción de las neuronas colinérgicas y la fallida neurotransmisión explican los síntomas observados en EA. La demencia podría mitigarse aumentando la actividad de la acetil colina en el cerebro.

Cummings y Back, 1998

Bartus, 2000

Hipótesis inflamatoria. En la neuropatología de EA es notable la presencia de marcadores de neuroinflamación (activación de microglia y astrocitos, componentes del complemento y citoquinas inflamatorias). Se ha observado Szekely et al., 2004 Tuppo y Arias, 2005 que el uso a largo plazo de antiinflamatorios no esteroideos (NSAID) pueden tener un efecto preventivo.

\section{Perspectivas terapéuticas}

La terapia utilizada en la actualidad trata de aliviar los síntomas cognitivos y de comportamiento experimentados por los pacientes, principalmente aumentando los niveles de concentración de los neurotransmisores (acetil colina) o bien modulando los sistemas de neurotransmisión (Geldmacher, 2003; Rogan y Lippa, 2002).

Las medicinas actualmente usadas para la EA -que fueron aprobadas por la administración de alimentos y medicinas (FDA) de Estados Unidos- incluyen inhibidores de la ACE para casos de leve a moderados, y antagonistas del receptor NMDA (N-metilo-D-aspartato) como la Memantina (Finucane, 2004), para casos moderados y severos. Muchos pacientes de Alzheimer presentan cambios bruscos de conducta y pueden tornarse violentos, apáticos y deprimidos. Estos trastornos conductuales asociados con la enfermedad representan una fuerte carga para familiares de los pacientes. La Memantina aparenta tener efectos beneficiosos sobre los síntomas -especialmente de agitación o agresión.

Los tres inhibidores de colinesterasas de uso común son Donepezil, Galantamina y Rivastigmina (Geldmacher, 2003; Loveman et al., 2006). Esto provino del hallazgo en la década de los 70, de una disminución significativa en la cantidad y actividad de enzimas sintéticas y degradadoras (colin esterasas y acetil transferasas) en las córtices límbicas y cerebrales. Mientras Donepezil y Galantamina únicamente inhiben a la ACE, la Rivastigmina inhibe también a la BCE. A pesar del amplio uso de este tipo de medicamentos, no se ha demostrado que estas intervenciones surtan efectos importantes en detener el avance de la enfermedad.

La aceptación de diferentes hipótesis que explican el origen y mecanismo patológico en la EA, ha conllevado a la proposición de alternativas terapéuticas diversas. En congruencia con la hipótesis de la cascada amilodea se ha propuesto prevenir la oligomerización del $\mathrm{AB}$ o estimular su remoción (Hardy y Selkoe, 2002; Hardy, 2006). Además, se podría procurar la inhibición parcial de las secretasas $\beta$ o $\gamma$, cuyas acciones conllevan a la producción de $\mathrm{AB}$. Sin embargo, este planteamiento se contradice con la hipótesis de PSEN que da 
importancia primaria a la pérdida de la función de PSEN en la patogénesis. Ésta plantea en particular que los inhibidores de secretasas $\gamma \beta$ en vez de mejorar, más bien agravarían la neurodegeneracion y la demencia. Según esto, una mejor estrategia terapéutica consistiría en estimular los procesos que dependen de la PSEN o aquellos que inhiban los procesos opuestos a PSEN (Shen y Kelleher, 2007).

Alternativamente, se ha investigado con inmunizaciones de $\mathrm{AB}$ en ratones, habiéndose demostrado la eficacia de los anticuerpos al $\mathrm{AB}$ en la reducción de depósitos amiloides (Bard et al., 2000 y 2003). Desafortunadamente, los ensayos clínicos de fase II en humanos usando como antígeno el AB1-42 tuvieron que detenerse debido a la presentación de meningoencefalitis aséptica en el 6\% de los pacientes tratados (Orgogozo et al., 2003). Actualmente, en nuevos ensayos se trata de prevenir la respuesta indeseada de células $\mathrm{T}$, así como el diseño de vacunas de $\mathrm{ADN}$ que expresen fragmentos de $\mathrm{AB}$.

Una de las posibles alternativas de terapias que marcha por buen camino es el uso de inhibidores de las enzimas kinasas que actúan sobre la proteína Tau. La dificultad ha sido identificar con certeza las kinasas de importancia biológica para Alzheimer que puedan actuar sobre los más de 30 sitios posibles de fosforilación. En particular, han recibido especial atención las kinasas GSK3B y cdk5/p25 (Tsai et al., 2004). Recientemente se ha reportado que la inhibición de GSK3B logra reducir la hiper fosforilación en muchos sitios y disminuye los niveles de agregación de Tau insoluble en ratones transgénicos que sobreexpresaban una forma mutante humana de Tau (Noble et al., 2005). Además, estudios recientes con ratones transgénicos demuestran la inhibición de la fosforilación de Tau por un nuevo compuesto de tipo indolocarbazol sintético, conllevando a un retraso de las deficiencias motoras características de EA (Le Corre et al., 2006). Este tipo de estudios sirve de apoyo al abordaje terapéutico del uso de inhibidores de la fosforilación de Tau como tratamiento modificador de la enfermedad.

Un hallazgo curioso de data reciente trata la relación entre Alzheimer y las proteínas Prion (PrP) causantes de otro tipo de neuropatologías, las encefalopatías espongiformes transmisibles (EET). Según esto, la proteína Prion en su estado normal inhibe la degradación de la APP (beta secretasas) y reduce la formación de AB (Parkin et al., 2007). Consecuentemente, podría considerarse la posibilidad terapéutica de usar compuestos farmacológicos que imiten la acción normal de PrP inhibiendo el corte de $\beta$ secretasas.

Más allá de las diferencias entre las hipótesis científicas, queda claro que el cuadro patológico característico de la demencia de la EA - muerte neuronal y pérdida de sinapsis y axones- ocurre como resultado de una compleja interacción de múltiples factores genéticos (Nee et $a l ., 2004$ ) y ambientales (Gatz et al., 2006). Urge que los expertos en el tema traten de encontrar explicaciones más integradoras sobre el origen de la enfermedad mucho antes de la presentación de los síntomas. Para ello, haría falta unir criterios con flexibilidad y aceptación de los resultados que validen las diversas hipótesis. Poder comprender las diversas conceptualizaciones que se han vertido sobre las bases biológicas de este mal conllevaría a converger en una teoría común que comprenda todas las demás. Sólo este tipo de abordaje podría encontrar tratamientos efectivos contra la disfuncionalidad neuronal. Un esfuerzo en esta dirección ha sido la conferencia organizada por la Universidad de Chile 
en noviembre pasado, logrando congregar por primera vez en la historia a los principales científicos que estudian el origen de la patología. ${ }^{4}$

La incorporación de la nuevas tecnologías y disciplinas de la era postgenómica en el estudio de la EA ha venido proporcionando un caudal de conocimientos que eventualmente podría conllevar a un diagnóstico temprano de la enfermedad y al desarrollo de mejores medicamentos. Se habla de la posibilidad de diseñar tratamientos (individualizados) que tomen en consideración las especificidades genómicas individuales.

Se espera que el uso de la farmacogenética y la farmacogenómica permitirá también optimizar la eficacia de los fármacos. Recientemente se ha descubierto que los enfermos de Alzheimer se distinguen por una mayor vulnerabilidad genética, comparados con la población general, por ser portadores de algunos de los más de 100 genes cuyas mutaciones o variaciones genéticas tienen una correlación con la enfermedad (Cacabelos, 2005). En europeos caucásicos el gen CYP2D6, uno de los responsables del metabolismo de los medicamentos en el cerebro, se presenta mutado en un porcentaje significativo (10-15\%) conllevando a mala respuesta terapéutica. Esta alteración, además, esta correlacionada con el alelo ApoE-e4/e4.

Una mejoría en la conceptualización de la enfermedad, así como la evaluación de las intervenciones médicas, requiere de: (1) la identificación de las cadenas de procesos y mecanismos que se encuentren desequilibrados y las rutas metabólicas críticas en la EA, (2) la definición de los factores más importantes de procesos perturbados como regeneración e inflamación y (3) la consideración de las variables fundamentales en EA -evaluación clínica, caracterización genética (genómica) y de proteínas séricas o de tejidos específicos (proteómica).

Algunos estudios genómicos y proteómicos recientes han aportado valiosa información. El trabajo de Finehout y colaboradores (2006) analizó comparativamente el patrón de más de 2 mil proteínas de pacientes de Alzheimer y de controles, identificando 23 proteínas de importancia para la EA.

También se ha estudiado el rol de los biomarcadores no sólo como herramientas en la investigación clínica de nuevos fármacos, sino también como marcadores para diagnósticos en las etapas previas a la aparición de la enfermedad, ya que hay evidencia de que la patología se desencadena muchos años antes de que aparezcan los síntomas clínicos. Se han utilizado biomarcadores del flujo cerebro-espinal para monitorear tratamientos experimentales como el de la inmunoglobulina intravenosa (IVIg) (Dodel et al., 2004; Solomon et al., 2007)

En un trabajo reciente, Eiman y colaboradores (2007) utilizaron microarreglos para estudiar más de medio millón de variantes genéticas (SNP) en la EA de tipo tardío. A través de un rastreo del genoma de 1,400 personas se identificó el gen GAB2, que en su estado normal protege al cerebro evitando la formación de ovillos neurofibrilares.

A pesar de todos estos avances, falta validación de los descubrimientos y aplicaciones concretas en la clínica y el laboratorio diagnóstico. Persiste la demanda urgente de nuevas 
terapias dirigidas a descifrar el mecanismo patogénico de la EA y que conduzcan, por tanto, a nuevos medicamentos con propiedades moduladoras de la enfermedad. De conocer mejor los orígenes de la enfermedad podrían procurarse métodos de diagnóstico precoz, así como mejores estrategias de prevención. Para países en vías de desarrollo, como Nicaragua, estos dos asuntos serían particularmente importantes dado que la situación de pobreza imposibilita costear los gastos médicos.

\section{Notas}

1 Conferencia presentada en el "Simposium sobre la Enfermedad de Alzheimer" realizado por la Fundación Alzheimer de Nicaragua el 21 de septiembre de 2007 (Día Mundial del Paciente con Alzheimer).

2 Informe de la Asociación de Alzheimer de EEUU. http://www.alz.org/living_with_alzheimers_latinos.asp; El reporte se puede encontrar en línea: www.alz.org/national/documents/report_sp_hispanic.pdf

3 Dr. Eddy Zepeda. Fundación Alzheimer de Nicaragua. Ver artículo (16 de septiembre de 2004) aparecido en El Nuevo Diario. En línea: http://archivo.elnuevodiario.com.ni/2004/septiembre/16-septiembre-2004/opinion/opinion-20040916-06.html

4 International Conference: "Current Hypotheses on Alzheimer's Disease". Disponible en http://www.adconferencechile.com/

\section{Referencias bibliográfícas}

ALZHEIMER, A. (1907). "Über eine eigenartige Erkrankung der Hirnrinde.” En Allgemeine Zeitschrift fur Psychiatrie und Psychisch-gerichtliche Medizin 64: 146-148. (Una enfermedad grave característica de la corteza cerebral).

BALES, K.R.; DODART, J.C.; DEMATTOS, R.B.; HOLTZMAN, D.M. \& PAUL, S.M. (2002). "Apolipoprotein E, amyloid, and Alzheimer disease". En Mol Interv. 2(6):363-75.

BARD, F. et al. (2000). "Peripherally administered antibodies against amyloid $\beta$-peptide enter the central nervous system and reduce pathology in a mouse model of Alzheimer disease". En Nature Medicine. Vol.6: 916-919.

BARD, F. et al. (2003). "Epitope and isotype specificities of antibodies to b-amyloid peptide for protection against Alzheimer's disease-like neuropathology". En PNAS. Vol. 100. 2023-2028.

BARTUS, R.T. (2000). "On neurodegenerative diseases, models, and treatment strategies: lessons learned and lessons forgotten a generation following the cholinergic hypothesis." datos

BOGDANOVIC, N.; APPELGREN, H. \& AXELMAN, K. (1994) "Amyloid precursor protein mutation causes Alzheimer's disease in a Swedish family". En Neuroscience letters. Vol. 168. 254-256.

BULlidO, M.J.; MARTÍNEZ-GARCÍA, A.; ARTIGA, M.J,; ALDUDO, J.; SASTRE, I.; GIL, P.; CORIA, F.; MUÑOZ, D.G.; HACHINSKI, V.; FRANK, A. \& VALDIVIESO, F. (2007). "A TAP2 genotype associated with Alzheimer's disease in ApoE-e4 carriers." En Neurobiol Aging 28(4):519-23.

BURGOS, J. S.; RAMIREZ, C.; SASTRE, I.; BULLIDO, M. J.; VALDIVIESO F., C.A. (2003). "ApoE4 is more efficient than E3 in brain access by herpes simplex virus type 1". En Neuroreport. Vol. 14. 1825-1827.

CACABELOS, R. (2005). "Pharmacogenomics and therapeutic prospects in Alzheimer's disease.” En Expert Opin Pharmacother. 6(12):1967-1987. 
CUMMINGS, J. L. \& BACK, C. (1998). "The Cholinergic Hypothesis of Neuropsychiatric Symptoms in Alzheimer's Disease”. En Am J Geriatr Psychiatry. Vol. 6. 64-78.

CUMMINGS, J. L. et al. (2004). "Reduction of Behavioral Disturbances and Caregiver Distress by Galantamine in Patients With Alzheimer's Disease”. En Am J Psychiatry Vol.161. 532-538. Exp Neurol. 163(2):495-529.

DODEL, R.C. et al. (2004). "Intravenous immunoglobulins containing antibodies against beta-amyloid for the treatment of Alzheimer's disease." En $J$ Neurol Neurosurg Psychiatry. 75(10):1472-4.

FINEHOUT, E.J. et al. (2007). "Cerebrospinal fluid proteomic biomarkers for Alzheimer's disease". En Ann Neurol. 61(2):120-9.

FINUCANE, T.E. (2004). "Memantine for patients with Alzheimer disease". En JAMA. Vol. 291(14). 1695.

FORSYTH, E. \& RITZLINE, P.D. (1998). “An overview of the etiology, diagnosis, and treatment of Alzheimer disease”. En Phys. Ther. Vol 78. 12: 1325-1331.

FULGA, T.A.; ELSON-SCHWAB, I.; KHURANA, V.; STEINHILB, M.L.; SPIRES, T.L.; HYMAN, B.T. \& FEANY, M.B. (2007). "Abnormal bundling and accumulation of F-actin mediates tau-induced neuronal degeneration in vivo. Nat Cell Biol. 2007 Feb;9(2):139-48.

GATZ, M.; REYNOLDS, C.A.; FRATIGLIONI, L.; JOHANSSON, B.; MORTIMER, J.A.; BERG, S.; FISKE, A. \& PEDERSEN, N.L. (2006). "Role of genes and environments for explaining Alzheimer disease.” En Arch Gen Psychiatry. 63(2):168-74

GELDMACHER, D. S. (2003). "Donepezil Is Associated with Delayed Nursing Home Placement in Patients with Alzheimer's Disease”. En Journal of the American Geriatrics Society. Vol. 51. 937-944.

GOATE, A. et al. (1991). "Segregation of a missense mutation in the amyloid precursor protein gene with familial Alzheimer's disease”. En Nature. Vol. 349. 704-706.

GREEN, R. C. et al. (2002). "Risk of Dementia Among White and African American Relatives of Patients With Alzheimer Disease". En JAMA. Vol. 287. 329-336.

HARDY, J. (1997). "The Alzheimer family of diseases: many etiologies, one pathogenesis?" En Proc Natl Acad Sci USA 94: 2095-2097.

HARDY, J. A. \& HIGGINS, G. A. (1992). "Alzheimer's disease: the amyloid cascade hypothesis.” En Science 256(5054):184-185.

HARDY, J. \& SELKOE, D. J. (2002). “The amyloid hypothesis of Alzheimer's disease: progress and problems on the road to therapeutics". En Science. 2002 Jul 19;297(5580):353-356.

HARDY, J. (2006). "Alzheimer's disease: the amyloid cascade hypothesis: an update and reappraisal.” En J Alzheimers Dis. 2006; 9:151-3.

KHACHATURIAN, A. S. et al. (2004) "Apolipoprotein E $\varepsilon 4$ Count Affects Age at Onset of Alzheimer Disease, but Not Lifetime Susceptibility”. En Arch Gen Psychiatry. Vol. 61. 518-524.

KING, M.E.; KAN, H.M.; BAAS, P.W.; ERISIR, A.; GLABE, C.G. \& BLOOM, G.S. “Tau-dependent microtubule disassembly initiated by prefibrillar beta-amyloid”. En J Cell Biol. 2006 Nov 20;175(4):541-546.

LE CORRE, S. et al. (2006) "An inhibitor of tau hyperphosphorylation prevents severe motor impairments in tau transgenic mice". En PNAS. Vol. 103. 9673-9678.

LEE, J.H.; CHENG, R.; SCHUPF, N.; MANLY, J.; LANTIGUA, R.; STERN, Y.; ROGAEVA, E.; WAKUTANI, Y.; FARRER, L.; ST GEORGE-HYSLOP, P. \& MAYEUX, R. (2007). “The association between genetic variants in SORL1 and Alzheimer disease in an urban, 
multiethnic, community-based cohort”. En Arch Neurol. 2007 Apr;64(4):501

LESNÉ, S.; KOH, M.T.; KOTILINEK, L.; KAYED, R.; GLABE, C.G.; YANG, A.; GALLAGHER, M: \& ASHE, K.H. (2006). "A specific amyloid-beta protein assembly in the brain impairs memory". En Nature. Vol. 440:284-285.

LIANG, X.; SCHNETZ-BOUTAUD, N.; BARTLETT, J.; ALLEN, M.J.; GWIRTSMAN, H.; SCHMECHEL, D.E.; CARNEY, R.M.; GILBERT, J.R.; PERICAK-VANCE, M.A. \& HAINES, J.L. (2007). "No Association between SNP rs498055 on Chromosome 10 and Late-Onset Alzheimer Disease in Multiple Datasets”. En Ann Hum Genet. 2007 Aug 24; [Epub ahead of print]

LOVEMAN, E.; GREEN, C.; KIRBY, J.; TAKEDA, A.; PICOT, J.; PAYNE, E. \& CLEGG, A. (2006). "The clinical and cost-effectiveness of donepezil, rivastigmine, galantamine and memantine for Alzheimer's disease”. En Health Technol Assess. 10(1):iii-iv, ix-xi, 1160.

MARTINS, C.A.R. et al. (2005). " $A P O E$ alleles predict the rate of cognitive decline in Alzheimer disease”. En Neurology. Vol. 65. 1888-1893.

NEE, L.E.; TIERNEY, M.C. \& LIPPA, C.F. (2004). “Genetic aspects of Alzheimer's disease, Pick's disease, and other dementias”. En Am J Alzheimers Dis Other Demen. 19(4):21925.

NOBLE, W. et al. (2005). "Inhibition of glycogen synthase kinase-3 by lithium correlates with reduced tauopathy and degeneration in vivo”.En PNAS. Vol. 102. 1211-1216.

ORGOGOZO, J.M.; GILMAN, S.; DARTIGUES, J.F.; LAURENT, B.; PUEL, M.; KIRBY, L.C.; JOUANNY, P.; DUBOIS, B.; EISNER, L.; FLITMAN, S.; MICHEL, B.F,; BOADA, M.; FRANK, A. \& HOCK, C. (2003). "Subacute meningoencephalitis in a subset of patients with AD after Abeta42 immunization.” En Neurology. 61(1):46-54.

PARKIN, E.T.; WATT, N.T.; HUSSAIN, I.; ECKMAN, E.A.; ECKMAN, C.B.; MANSON, J.C.; BAYBUTT, H.N.; TURNER, A.J. \& HOOPER, N.M. (2007). "Cellular prion protein regulates beta-secretase cleavage of the Alzheimer's amyloid precursor protein". En Proc Natl Acad Sci (USA).104(26):11062-7.

PLASSMAN, B.L.; LANGA, K.M.; FISHER, G.G.; HEERINGA, S.G.; WEIR, D.R.; OFSTEDAL, M.B.; BURKE, J.R.; HURD, M.D.; POTTER, G.G.; RODGERS, W.L.; STEFFENS, D.C.; WILLIS, R.J. \& WALLACE, R.B. (2007). "Prevalence of Dementia in the United States: The Aging, Demographics, and Memory Study”. En Neuroepidemiology. 2007 Oct 29;29(1-2):125-132

RAPOPORT, M.; DAWSON, H.N.; BINDER, L.I.; VITEK, M.P. \& FERREIRA, A. (2002). "Tau is essential to beta -amyloid-induced neurotoxicity”. En Proc Natl Acad Sci (USA) 99(9):6364-6369.

ROBERSON, E.D.; SCEARCE-LEVIE, K.; PALOP, J.J.; YAN, F.; CHENG, I.H.; WU, T.; GERSTEIN, H.; YU, G.Q. \& MUCKE, L. (2007). "Reducing endogenous tau ameliorates amyloid betainduced deficits in an Alzheimer's disease mouse model". En Science 316(5825):750-4.

RODRÍGUEZ-MANOTAS, M.; AMORÍN-DÍAZ, M.; CAÑIZARES-HERNÁNDEZ, F.; RUÍZESPEJO, F.; MARTÍNEZ-VIDAL, S.; GONZÁLEZ-SARMIENTO, R.; MARTÍNEZHERNÁNDEZ, P. \& CABEZAS-HERRERA, J. (2007). "Association study and metaanalysis of Alzheimer's disease risk and presenilin-1 intronic polymorphism”. En Brain Res. 2007 Sep Vol. 19.1170. 119-28.

ROGAEVA, E.; MENG, Y.; LEE, J.H.; GU, Y.; KAWARAI, T.; ZOU, F.; KATAYAMA, T.; BALDWIN, C.T. \& CHENG, R. (2007) "The neuronal sortilin-related receptor SORL1 is genetically 
associated with Alzheimer disease". En Nat Genet. 39(2):168-77.

ROGAN, S. \& LIPPA, C.F. (2002) "Alzheimer's disease and other dementias: a review". En Am J Alzheimers Dis Other Demen. 17(1):11-7.

ROMAS, S. N. et al. (2002) "Familiar Alzheimer Disease Among Caribbean Hispanics". En Arch Neurol. Vol. 59. 87-91.

SAUNDERS, A,M.; HULETTE, O.; WELSH-BOHMER, K.A.; SCHMECHEL, D.E.; CRAIN, B.; BURKE, J.R.; ALBERTS, M.J.; STRITTMATTER, W.J.; BREITNER, J.C.; ROSENBER,G. C. (1996). "Specificity, sensitivity, and predictive value of apolipoprotein-E genotyping for sporadic Alzheimer's disease”. En Lancet. Vol. 1996 Jul 13; 348(9020):90-3

SAURA, C. A. et al. (2005). "Conditional Inactivation of Presenilin 1 Prevents Amyloid Accumulation and Temporarily Rescues Contextual and Spatial Working Memory Impairments in Amyloid Precursor Protein Transgenic Mice". En The Journal of Neuroscience, Vol. 25. 6755-6764

SCHELLENBERG, G.D.; BIRD, T.D.; WIJSMAN, E.M.; ORR, H.T.; ANDERSON, L.; NEMENS, E.; WHITE, J.A.; BONNYCASTLE, L.; WEBER, J.L. \& ALONSO, M.E. (1992). "Genetic linkage evidence for a familial Alzheimer's disease locus on chromosome 14”. En Science Vol. 258. 668-71.

SELKOE, D.J. (1991). "The molecular pathology of Alzheimer's disease”. En Neuron. Vol. 6(4). 487-498.

SHEN, J. \& KELLEHER, R. J., III. (2007) “The presenilin hypothesis of Alzheimer's disease: Evidence for a loss-of-function pathogenic mechanism”. En PNAS. Vol. 104. 403-409.

SOLOMON,B.(2007). "IntravenousimmunoglobulinandAlzheimer's diseaseimmunotherapy." En Curr Opin Mol Ther. 9(1):79-85.

SZEKELY, C.A.; THORNE , J.E.; ZANDI, P.P.; EK, M.; MESSIAS, E.; BREITNER, J.C. \& GOODMAN, S.N. (2004). "Nonsteroidal anti-inflammatory drugs for the prevention of Alzheimer's disease: a systematic review". En Neuroepidemiology 23(4):159-69

TANZI, R.E.; GUSELLA, J.F.; WATKINS, P.C.; BRUNS, G.A.; ST GEORGE-HYSLOP, P.; VAN KEUREN, M.L.; PATTERSON, D.; PAGAN, S.; KURNIT, D.M. \& NEVE, R.L. (1987). "Amyloid beta protein gene: cDNA, mRNA distribution, and genetic linkage near the Alzheimer locus". En Science. Vol. 235. 880-884.

TSAI, L.H.; LEE, M.S. \& CRUZ, J. (2004) “Cdk5, a therapeutic target for Alzheimer's disease? En Biochim Biophys Acta. 2004 Mar 11;1697(1-2):137-42.

TUPPO, E.E. \& ARIAS, H.R. (2005). “The role of inflammation in Alzheimer's disease”. En Int J Biochem Cell Biol. 2005 Feb;37(2):289-305.

VAN BROECKHOVEN, C.L. (1995). "Molecular genetics of Alzheimer disease: identification of genes and gene mutations”. Eur. Neurol. 35(1):8-19.

ZHANG, Q.; POWERS, E.T.; NIEVA, J.; HUFF, M.E.; DENDLE, M.A.; BIESCHKE, J.; GLABE, C.G.; ESCHENMOSER, A.; WENTWORTH, P. JR,; LERNER, R.A. \& KELLY, J.W. (2004). "Metabolite-initiated protein misfolding may trigger Alzheimer's disease". En Proc Natl Acad Sci (USA) 101(14):4752 